\title{
Influence of Strain Rate on Dynamic Recrystallization Behaviors of a Near- $\alpha$ Titanium Alloy During Isothermal Hot-tensile Deformation:Experimental and Simulative Investigations
}

\author{
Peng LIN ${ }^{\mathrm{a} *}$, Yong-Gang $\mathrm{HAO}^{\mathrm{b}}$, Wang-Jun $\mathrm{CHENG}^{\mathrm{c}}$ and Cheng-Zhong $\mathrm{CHI}^{\mathrm{d}}$ \\ College of Materials Science and Engineering, Taiyuan University of Technology, Taiyuan 030024, \\ PR China
}

alinpeng@tyut.edu.cn, ’haoyonggang0102@link.tyut.edu.cn, 'chengwangjun2008@126.com,

*Corresponding author

Keywords: Near-a titanium alloy, Strain rate,Dynamic recrystallization, Numerical simulation

\begin{abstract}
Dynamic recrystallization (DRX) behaviors of a near- $\alpha$ titanium alloy during isothermal hot-tensile tests were investigated with finite element simulation and electron backscattered diffraction (EBSD) test. The results show that the DRX behavior of the alloy is strongly sensitive to the strain rate, i.e., the average grain size increases with the decrease in strain rate, and the predicted average grain size of recrystallized grains with finite element method (FEM) based on cellular automata (CA) modeling are in good agreement with the experimental results by EBSD.
\end{abstract}

\section{Introduction}

Titanium alloys are widely used in aerospace and aviation industries due to their excellent properties, such as good damage tolerance, fracture toughness, fatigue resistance and creep resistance, etc [1-3]. In order to achieve proper properties of the material, it is essential to study the dependence of the microstructure evolution, such as dynamic recrystallization (DRX), static recrystallization (SRX), dynamic recovery (DRV), on processing parameters. During DRX, new recrystallized grains (re-grains) originate and result in microstructural changes, especially for grain size which varies largely with strain rate. Hence, it is the key to establish the relation between grain size and strain rate to analyze and predict DRX microstructure evolution of the alloy.

Many studies have been focused on the influence of various processing parameters on DRX behaviors of materials. The DRX behaviour curves of the near- $\alpha$ titanium alloy IMI834 in various strain rates and temperatures were investigated by Balasundar et al. [1]. Chuan et al. [4] simulated the isothermal hot compression process of a near- $\alpha$ titanium alloy by combining a CA model with a crystal plasticity FEM, with which the strain distribution, average grain size and grains growth velocity were partly predicted. Presently, although the DRX microstructures of materials and alloys in thermomechanical processing have been experimentally studied, there have been few theories to directly establish the relationship between microscopic grain size and strain rate.

In the present work, in order to study the influence of strain rate on DRX and predict microstructure evolution exactly, isothermal hot-tensile tests of near- $\alpha$ titanium alloy were carried out at various temperatures and strain rates. The DRX process and average grain size were numerically simulated with FEM based on CA modeling. Microstructure evolution were experimentally measured by EBSD.

\section{Numerical}

\section{Parameter Details}

DRX behaviors of the near- $\alpha$ titanium alloy were simulated with FE software Deform-3D V10.2. Ignoring the elastic deformation, the hot-tensile specimen with dimensions of $24 \times 5.5 \times 2 \mathrm{~mm}$ in deformation zone was meshed into 20000 grids and a constant shear friction factor with the lubricating of 0.3 was employed. The upper and lower dies were regarded to be rigid with the same 
temperature as the hot-tensile specimens. The complete hot-tensile simulation was performed in 480 steps and the upper die in each step was equal to $0.1 \mathrm{~mm}$. The velocities of the upper die were $7.2 \mathrm{~mm} / \mathrm{s}, 0.72 \mathrm{~mm} / \mathrm{s}, 0.072 \mathrm{~mm} / \mathrm{s}$, respectively. The parameters of FE model were list in Table $\mathbf{1}$.

Table 1 Parameter details of FE model

\begin{tabular}{ll}
\hline Parameters & Value \\
\hline Environment temperature $/{ }^{\circ} \mathrm{C}$ & 20 \\
Billet temperature $/{ }^{\circ} \mathrm{C}$ & $850 / 900 / 950$ \\
Dies temperature $/{ }^{\circ} \mathrm{C}$ & $850 / 900 / 950$ \\
Billet material & Near- $\alpha$ titanium alloy \\
Die smaterial & $\mathrm{GH}-4169$ \\
Shear friction factor & 0.3 \\
Heat transfer coefficient $/ \mathrm{W} /\left(\mathrm{m} 2 \times{ }^{\circ} \mathrm{C}\right)$ & 16.8 \\
Grid number of the billet & 20000 \\
Strain rate of the billet $/ \mathrm{s}^{-1}$ & $0.003,0.03,0.3$ \\
Initial grain size/um & 6.28 \\
\hline
\end{tabular}

\section{Cellular Automata Model}

For microstructure simulation, FEM based on CA modeling was used. CA spaces were divided into $100 \times 100$ square lattices. The size of each lattice represented $10 \mu \mathrm{m}$ for actual dimensions of the specimen and the simulative area corresponded to $1 \times 1 \mathrm{~mm}^{2}$ in a hot-tensile specimen. CA algorithm has been applied to simulate DRX, which involves calculating the state of a local cell as a function of external inputs (such as strain, strain rate, and temperature, etc.) and the state of its local neighbors [5-7]. That is, if a particular cell switches state (recrystallization, phase transformation, etc.), then its neighbors will follow as well. Each cell consists of four main state variables, including the crystal orientation variable, the dislocation density variable, one order parameter variable and one fraction variable [8-11].

\section{Experimental}

The hot-rolled near- $\alpha$ titanium alloy sheet $(2 \mathrm{~mm}$ in thickness) with the composition of Ti-6.0Al-1.21Nb-9.04Zr-3.88Sn-1.59W-0.28Si (wt.\%) was utilized for isothermal hot-tensile test. Tensile specimens were prepared along the rolling direction, with a gauge length of $24 \mathrm{~mm}$ and a width of $5 \mathrm{~mm}$. Isothermal uniaxial-tensile tests were performed on an Instron 1361 machine attached with a high temperature furnace at the temperatures of $850^{\circ} \mathrm{C}, 900^{\circ} \mathrm{C}, 950^{\circ} \mathrm{C}$ and strain rates of $0.003 \mathrm{~s}^{-1}, 0.03 \mathrm{~s}^{-1}, 0.3 \mathrm{~s}^{-1}$. The hot-tensile samples were characterized with EBSD (Quanta 200 FEG-SEM) method. The EBSD samples were prepared by electrochemical polishing in a solution of $6 \%$ perchloric acid, $34 \%$ n-butanol and $60 \%$ carbinol at $-30{ }^{\circ} \mathrm{C}$ with an applied current of $70 \mathrm{~mA}$ and a voltage of $30 \mathrm{~V}$.

\section{Results and Discussion}

\section{Stress-strain Curves}

True stress-strain curves of the alloy are demonstrated in Fig. 1. The true stress increases sharply at a lower strain and decrease smoothly after yielding, which means softening (recrystallization) begins to offset the work hardening when the strain reaches the critical value for DRX. When the strain approximates to 0.06 0.08, the flow stress reaches a peak owing to a balance between softening and hardening. When the strain exceeds the critical value, the flow stress decreases gradually, indicating that the extent of softening is greater than that of hardening. Flow stress increases rapidly when the strain rate increases from $0.003 \mathrm{~s}^{-1}$ to $0.3 \mathrm{~s}^{-1}$ at the same temperature. This is because larger strain rate requires more dislocations to be driven in unit time and the flow stress increment results from the increase of dislocation density. 


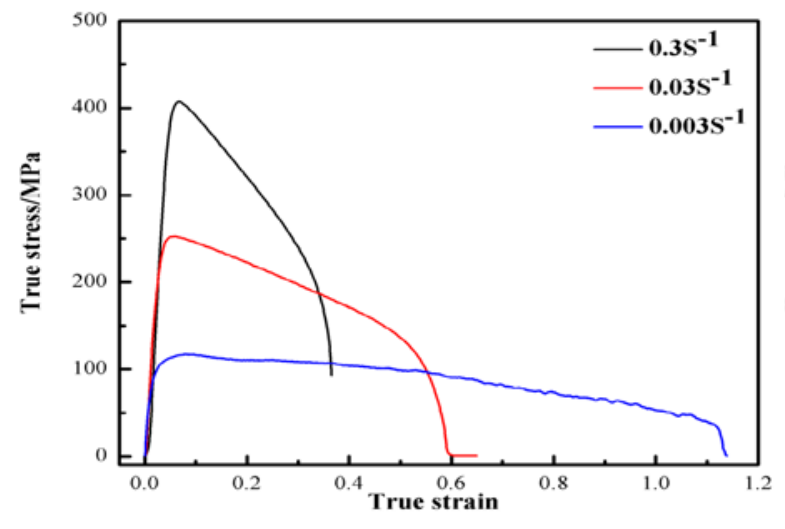

(a) $850^{\circ} \mathrm{C}$

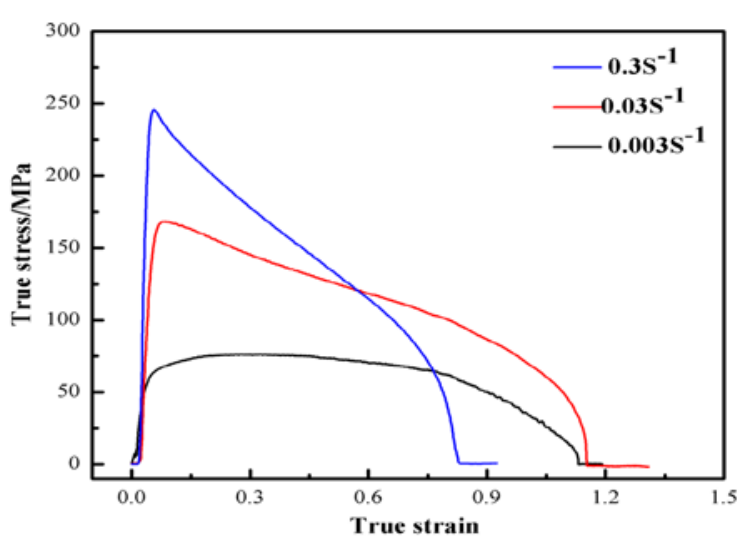

(b) $900{ }^{\circ} \mathrm{C}$

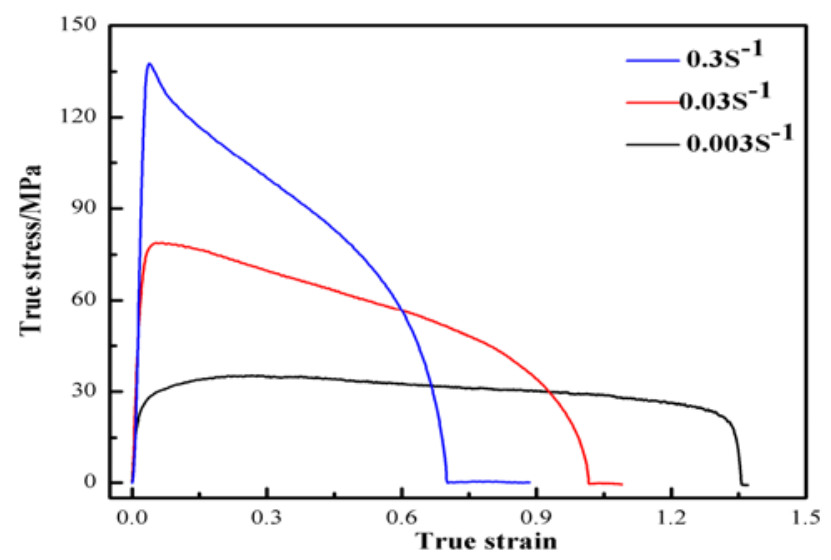

(c) $950^{\circ} \mathrm{C}$

Fig. 1. True stress-strain curves at various temperatures and strain rates.

Initial microstructure and grain size distribution of the alloy are shown in Fig. 2. The microstructure in the scanned area distributes heterogeneously. The grain size varied in a wide range with the mean size of $6.28 \mu \mathrm{m}$. The near- $\alpha$ titanium alloy is mainly discussed on its $\alpha$ phase due to the minority and instability of the primary $\beta$ phase during the isothermal hot deformation.

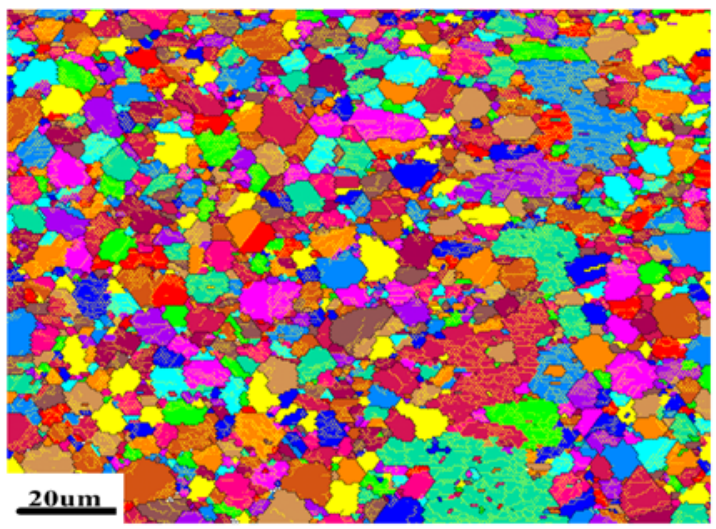

(a)

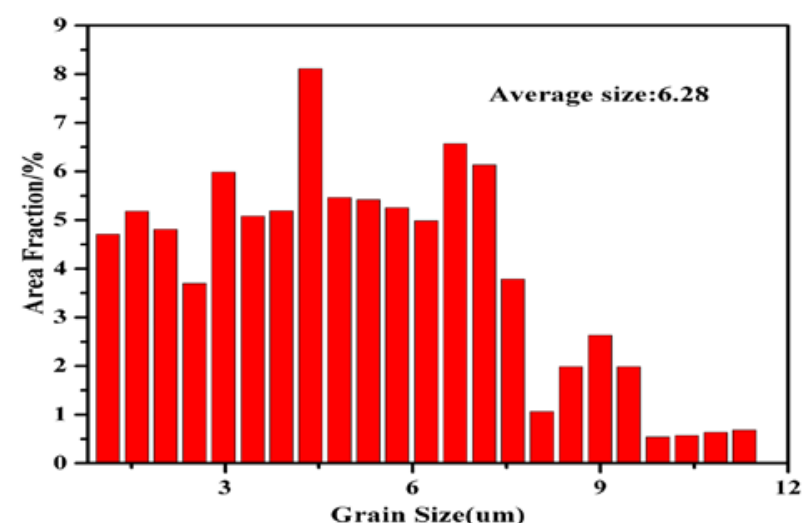

(b)

Fig. 2. EBSD microstructure (a) and grain size distribution (b) of the near- $\alpha$ titanium alloy

\section{Simulative Results and Discussion}

Fig. 3 reveals the effective strain distribution with elongation of $200 \%$. The maximum effective strain of 2.05 is observed at deformed zone (P1) and is approximately zero at undeformed zone (P2). At zone P1, superplastic deformation occurs due to the equilibrium effect between work hardening 
and dynamic softening. The strain level in this area is higher compared with the zone P2. Therefore, DRX behaviors studied in the present work concentrate upon zone P1.

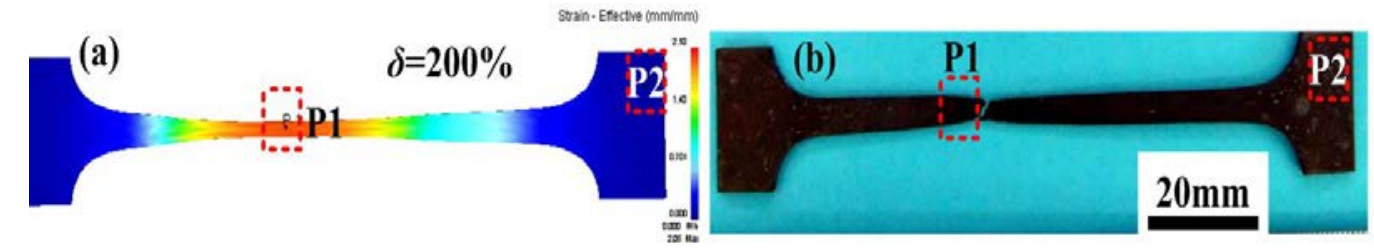

Fig. 3. Hot tensile specimen $\left(\mathrm{T}=900^{\circ} \mathrm{C}, \dot{\varepsilon}=0.3 \mathrm{~s}-1\right)$ : (a) the simulated; (b) the experimental.

Fig. 4 shows the simulated microstructure of the alloy specimens in deformed zone $\mathrm{P} 1$ at $900^{\circ} \mathrm{C}$ and a strain rate of $0.03 \mathrm{~s}^{-1}$ with various elongations $(50 \%, 80 \%, 120 \%, 200 \%)$. New re-grains mainly generate at the boundaries of original grains. The larger the elongation was, the more new DRX grains formed in the hot tension. Grain boundaries bend obviously and nucleation area of DRX expands largely. Original grains are gradually replaced by re-grains due to its growth by boundaries migrating.
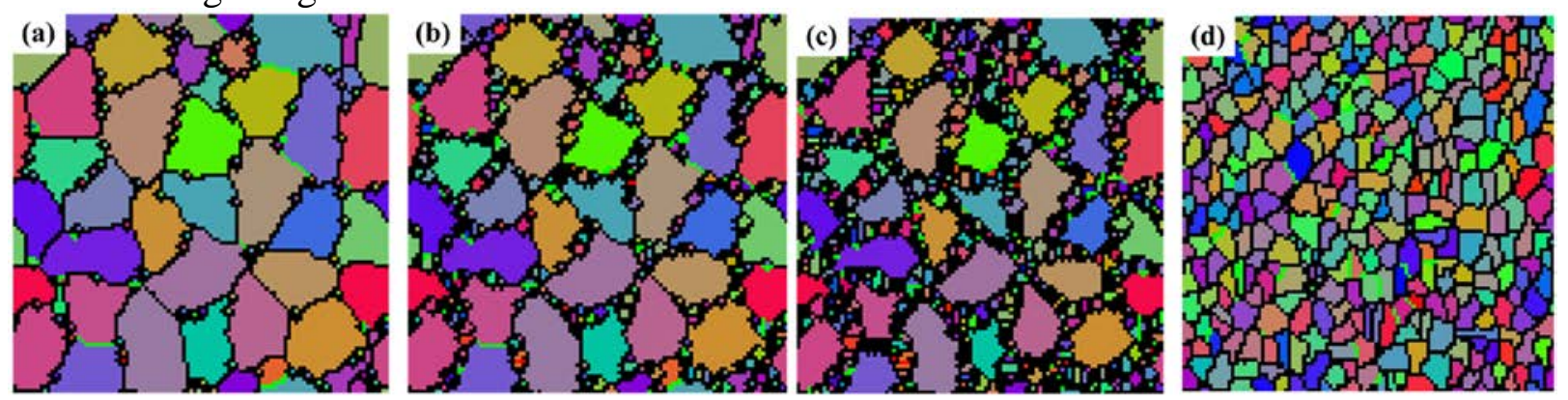

Fig. 4. Simulated microstructure of the alloy specimens in deformed zone at $900^{\circ} \mathrm{C}$ and strain rate of $0.3 \mathrm{~s}^{-1}$ : (a) elongations of $50 \%$; (b) $80 \%$; (c) $120 \%$; (d) $200 \%$.

The size of re-grains is dependent on the level of strain rate and temperature at the fully recrystallized area [12]. To verify the influence of strain rate on DRX, the simulation was conducted under various strain rates. The simulated microstructure of the tensile specimens at $900^{\circ} \mathrm{C}$, elongation of $200 \%$ and strain rates of $0.003 \mathrm{~s}^{-1}$ and $0.03 \mathrm{~s}^{-1}$ are indicated in Fig. 5. Obviously, due to DRX, grains in the deformed zone P1 (Fig. 5a and c) are refined compared with that in the undeformed zone P2 (Fig. 5b), and the average re-grain size decreases with the increase of strain rate. That is because the stored energy and nucleus in the form of deformation defects such as dislocations and grain boundaries that are indispensable for DRX are less restored during higher strain rate deformation. The re-grains gets increasingly smaller due to higher driving force for nucleation. In addition, the greater the nucleation rate of DRX is, the required time to reach a steady state of DRX is shorter, making the new formed re-grains difficult to grow up. 

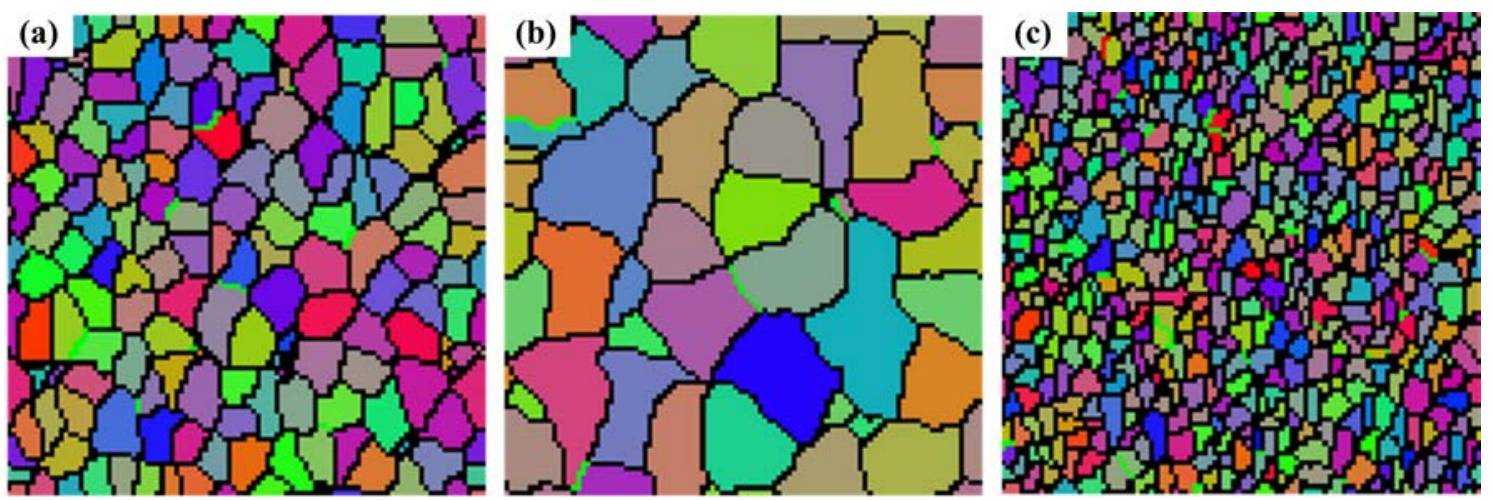

Fig. 5. Simulated microstructure of the tensile specimens with elongation of $200 \%$ at $\mathrm{T}=900^{\circ} \mathrm{C}$ : (a) deformed zone P1, at $\dot{\varepsilon}=0.003 \mathrm{~s}^{-1}$; (b) undeformed zone P2 (c) deformed zone P1 at $\dot{\varepsilon}=0.03 \mathrm{~s}^{-1}$.

Fig. 6 indicates the simulated grain histograms for specimens deformed at $900^{\circ} \mathrm{C}$.
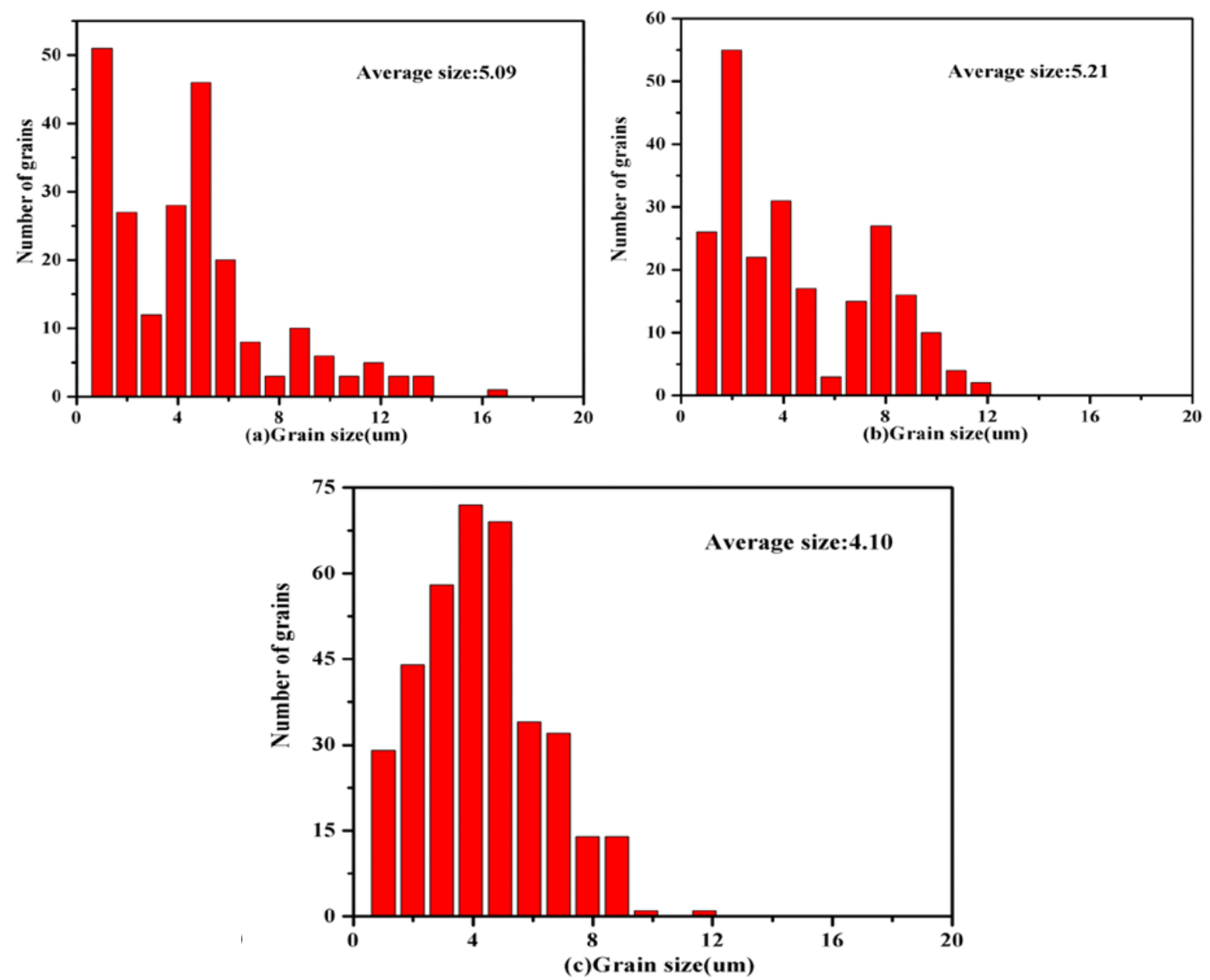

Fig. 6. Simulated grain histograms of the tensile specimens with elongation of $200 \%$ at $\mathrm{T}=900^{\circ} \mathrm{C}$ : (a) deformed zone P1, at $\dot{\varepsilon}=0.003 \mathrm{~s}^{-1}$; (b) undeformed zone P2 (c) deformed zone P1 at $\dot{\varepsilon}=0.03 \mathrm{~s}^{-1}$.

Average grain size varies with various strain rates. In simulation, average grain size is $5.09 \mu \mathrm{m}$ in deformed zone (P1) at the strain rate of $0.003 \mathrm{~s}^{-1}$, while $4.10 \mu \mathrm{m}$ at the strain rate of $0.03 \mathrm{~s}^{-1}$. Average grain size at the undeformed zone (P2) is $5.21 \mu \mathrm{m}$ which is a little larger than that of deformed zone (P1). The number of grains in unit region possesses the largest at deformed zone (P1) with the higher strain rate of $0.03 \mathrm{~s}^{-1}$ in Fig. 6c. There exists two potential factors to contribute to above 
results. One is that grain growth in a lower strain rate of $0.003 \mathrm{~s}^{-1}$ stays a predominant factor at the deformed zone (P1). Another is that the nucleation site is connected with the stored energy.

\section{Experimental Results and Discussion}

EBSD microstructure of the tensile specimens with an elongation of $200 \%$ is shown in Fig. 7 and Fig. 8. Compared to the as-received samples, the hot-tensile specimens at $900^{\circ} \mathrm{C}$ exhibit the dominant DRX at various strain rates. Average grain size of $5.16 \mu \mathrm{m}$ (Fig. $7 \mathrm{~b}$ ) at undeformed zone is larger than that at deformed zone of $5.07 \mu \mathrm{m}$ (Fig. 7a) and $3.72 \mu \mathrm{m}$ (Fig. 7c). Average grain size $(3.72 \mu \mathrm{m})$ at a higher strain rate is the smaller than that at lower strain rate $(5.07 \mu \mathrm{m})$, which indicates that the extent of DRX increased with the strain rate and higher strain rate contributes to the grain refinement.
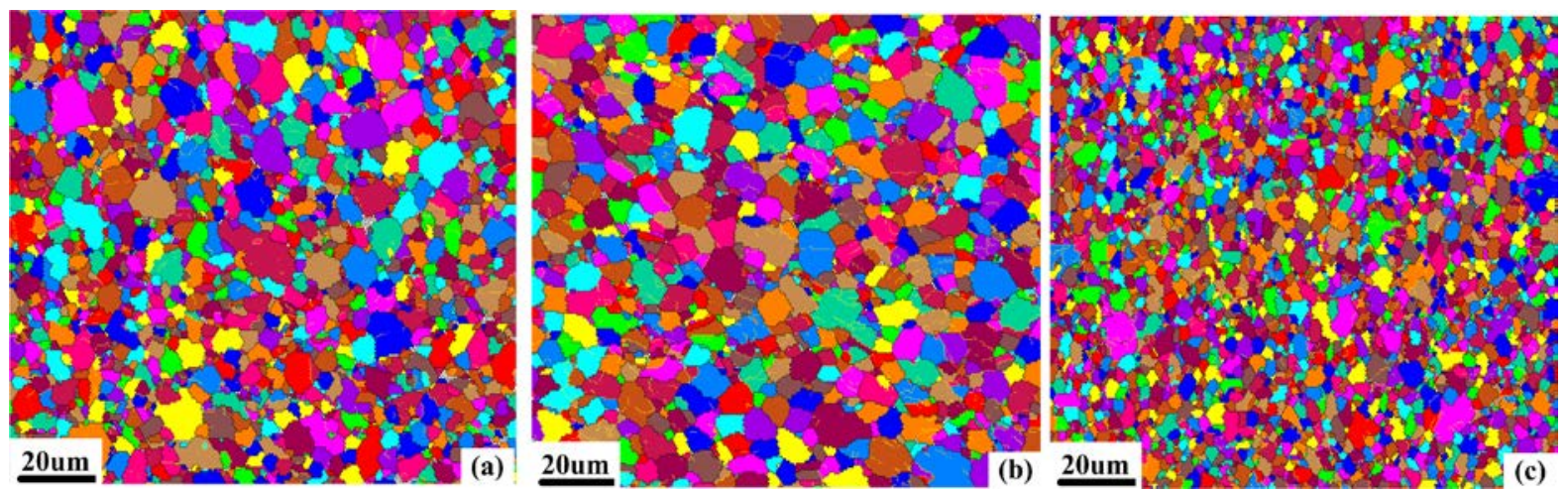

Fig. 7. EBSD microstructure of the tensile specimens with elongation of $200 \%$ at $900^{\circ} \mathrm{C}$ : (a) deformed zone at $\dot{\varepsilon}=0.003 \mathrm{~s}^{-1}$; (c) undeformed zone; (d) deformed zone at $\dot{\varepsilon}=0.03 \mathrm{~s}^{-1}$.
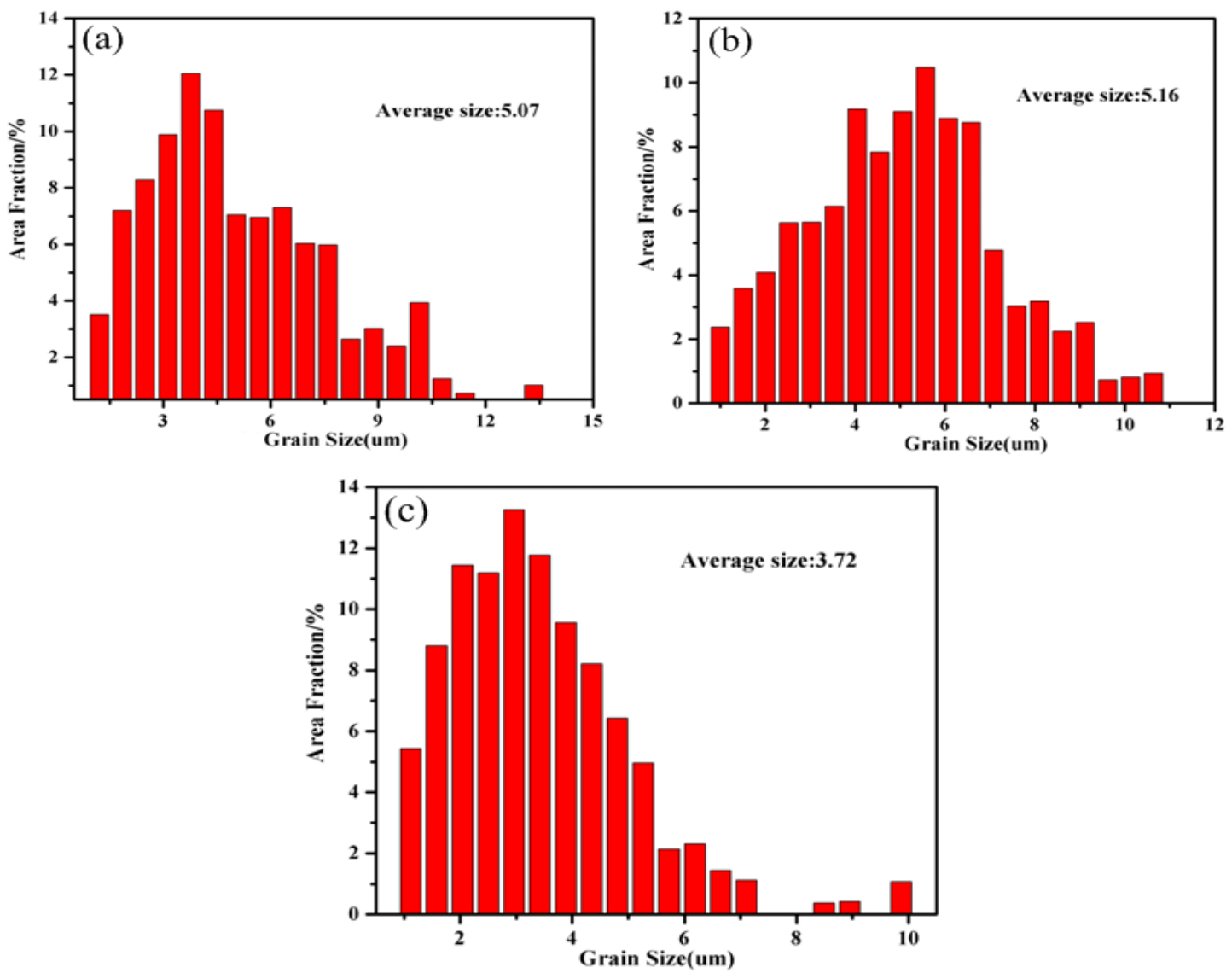

Fig. 8. Grain distribution of the tensile specimens with elongation of $200 \%$ at $900^{\circ} \mathrm{C}$ : (a) deformed zone at $\dot{\varepsilon}=0.003 \mathrm{~s}^{-1}$; (c) undeformed zone; (d) deformed zone at $\dot{\varepsilon}=0.03 \mathrm{~s}^{-1}$. 
The simulated and experimental average sizes for the near- $\alpha$ titanium alloy are shown in Table 2 . The average relative deviation is $9.3 \%$, indicating the predicted average grain size of re-grains by FEM CA modeling are in good agreement with the experimental results by EBSD.

Table 2. The simulated and the experimental average grain sizes.

\begin{tabular}{llcllc}
\hline Temperature/ $\mathrm{C}$ & Strain $^{\text {ate } / \mathrm{s}^{-1}}$ & Elongation\% & Experimental $/ \mu \mathrm{m}$ & simulated $/ \mu \mathrm{m}$ & Error\% \\
\hline 900 & 0.003 & $200 \%$ & 5.07 & 5.83 & $13 \%$ \\
900 & 0.03 & $200 \%$ & 3.72 & 4.10 & $9 \%$ \\
900 & 0.3 & $200 \%$ & 2.82 & 2.96 & $6 \%$ \\
\hline
\end{tabular}

\section{Conclusions}

The DRX behavior of a near- $\alpha$ titanium alloy is strongly sensitive to the deformation strain rate, i.e., the average grain size increases with the decrease in deformation strain rate, and the predicted average grain size of re-grains with finite element method (FEM) based on cellular automata (CA) modeling are in good agreement with the experimental results by EBSD.

\section{Acknowledgments}

This work was supported by the National Natural Science Foundation of China (No. 51505323).

\section{References}

[1] Balasundar, I.; Raghu, T.; Kashyap, B.P. Hot working and geometric dynamic recrystallisation behaviour of a the near- $\alpha$ titanium alloy with acicular microstructure. Mater. Sci. Eng. A. 2014, 600, 135-144.

[2] Thomas, M.; Lindley, T.; Rugg, D.; Jackson, M. The effect of shot peening on the microstructure and properties of a near-alpha titanium alloy following high temperature exposure. Acta Mater. 2012, 60, 5040-5048.

[3] Mishra, H.; Satyanarayana, D.V.; Nandy, T.K.; Sagar, P.K. Effect of trace impurities on the creep behavior of a near- $\alpha$ titanium alloy. Scripta Mater. 2008, 59, 591-594.

[4] Chuan, W.; He, Y.; Wei, L.H. Modeling of discontinuous dynamic recrystallization of a near-atitanium alloy IMI834 during isothermal hot compression by combining a cellular automaton model with a crystal plasticity finite element method. Comput. Mater. Sci. 2013, 79, 944-959.

[5] Rauch, L.; Madej, L.; Spytkowski, P.; Golab, R. Development of the cellular automata framework dedicated for metallic materials microstructure evolution models. Arch. Civil. Mech. Eng.2014, 243, 1-14.

[6] Ding, R.; Guo, Z.X. Coupled quantitative simulation of microstructural evolution and plastic flow during dynamic recrystallization. Acta Mater. 2001, 49, 3163-3175.

[7] Kugler, G.; Turk, R. Modeling the dynamic recrystallization under multi-stage hot deformation Acta Mater. 2004, 52, 4659-4668.

[8] Ma, A.; Roters, F.; Raabe, D. Studying the effect of grain boundaries in dislocation density based crystal-plasticity finite element simulations. Int. J. Solid. Struct. 2006, 43, 7287-7303.

[9] Harren, S.V. Theory of evolution of crystal lattice orientation density and state variables in euler space. Int. J. Plast.1997, 13, 59-74.

[10] Hore, S.; Das, S.K.; Banerjee, S.; Mukherjee, S.; A multiscale coupled Monte Carlo model to characterize microstructure evolution during hot rolling of Mo-TRIP steel. Acta Mater. 2013, 61, 
7251-7259.

[11] Liu, X.; Lee, L.X.; He, F.Y.; Zhou, J.; Zhu, B.W.; Zhang, L.Q. Simulation on dynamic recrystallization behavior of AZ31 magnesium alloy using cellular automaton method coupling Laasraoui-Jonas model. Trans. Nonferrous Met. Soc. China. 2013, 23, 2692-2699.

[12] Sakai, T.; Belyakov, A.; Kaibyshev, R.; Miura, H.; Jonas, J. J. Dynamic and post-dynamic recrystallization under hot, cold and severe plastic deformation conditions. Prog. Mater. Sci. 2014, 60, 130-207. 